\title{
Repeatability of methane production in cattle fed concentrate and forage diets*
}

\author{
J.P. Goopy ${ }^{1}$ and R.S. Hegarty ${ }^{2}$ \\ ${ }^{1}$ School of Rural Science and Agriculture, University of New England, Armidale, Australia \\ ${ }^{2}$ Beef Industry Centre, NSW Department of Agriculture, Armidale, Australia
}

\begin{abstract}
Eight Angus steers whose methane emissions had had been found to be higher or lower than predicted when fed a commercial feedlot diet were re-tested on a medium quality forage diet. Methane emissions were within published ranges $\left(136.4 \mathrm{~g} \mathrm{~d}^{-1}\right)$, but differences in actual vs predicted production between high and low ranked animals were diminished and several animals changed in rankings. This suggests that methane emission characteristics may not persist over time, and that any selection of animals for low methane emission may need to be diet specific.
\end{abstract}

KEY WORDS: methane, ruminant, sulphur hexafluoride, forage

\section{INTRODUCTION}

Anthropogenic methane production is a significant contributor to the greenhouse effect, and approximately $12 \%$ of this is generated by ruminants (Crutzen et al., 1986). Opportunities for amelioration of methane production by ruminants may include: a. selection for animals which produce relatively less methane, and/or b. dietary manipulation or management of animals' internal environment which predispose them to the production of lower levels of methane.

Blaxter and Clapperton (1965) observed that animals produce relatively more methane per unit energy intake on forage rather than concentrate but an important question that has remained unresolved is whether animals that are assessed as high or low $\mathrm{CH}_{4}$ emitters on one type of diet retain the characteristic or rank on other feed types.

Direct measurement of methane production in respiratory chambers is constrained by the relatively small number of animals that can be screened for

\footnotetext{
* Supported by Meat and Livestock Australia

${ }^{1}$ Corresponding author: e-mail: jgoopy@pobox.une.edu.au
} 
methane production. The development of indirect techniques using tracer gases (Johnson et al., 1994) has facilitated the screening of relatively large numbers of animals in the field. This has led to identification of animals that exhibit higher or lower methane production than would be expected based on body size and intake (Pinares-Patiño et al., 2003; Hegarty et al., 2004).

The purpose of this trial was to determine if cattle producing more or less methane than expected demonstrate this characteristic when changed from a concentrate to an exclusively forage diet.

\section{MATERIAL AND METHODS}

\section{Animal management and feeding}

In a preceding study, methane production had been individually measured on 91 Angus steers fed a commercial feedlot diet (12.1MJ ME/kg DM, 16.0\% $\mathrm{CP}, 100 \mathrm{ppm}$ Rumensin $\left.{ }^{\circledR}\right) . \mathrm{CH}_{4}$ production was expressed as a percentage of that predicted by the general equation of Blaxter and Clapperton (1965) and a subset of steers producing more (HIGH emitters; $n=6$ ) or less (LOW emitters; $n=6$ ) $\mathrm{CH}_{4}$ than predicted was identified. Emissions from these were measured again on the same feedlot diet (Period 1). The cattle were then depastured for several months.

Eight animals $(627 \pm 49.2 \mathrm{~kg})$ were selected for further study (Period 2) and $\mathrm{CH}_{4}$ production re-measured, during which the animals were housed individually in adjacent feedlot pens $(15 \mathrm{~m} \times 25 \mathrm{~m})$ with unrestricted access to water and chaffed forage sorghum hay (Sorghum bicolour c.v. Superdan; 8.1 MJ ME/kg $\mathrm{DM}, 11.2 \% \mathrm{CP})$. Animals were adapted to the diet for $15 \mathrm{~d}$ before measurements were made, with ad libitum feed provided once daily, and refusals collected and weighed. During the measurement period, feed and refusals were sub-sampled daily and analysed (DM, CP, ADF, NDF and ME) at the trial's end.

\section{Methane measurement}

Enteric $\mathrm{CH}_{4}$ production was measured using the sulphur hexafluoride $\left(\mathrm{SF}_{6}\right)$ tracer technique (Johnson et al., 1994) as modified by Hegarty et al. (2003). The $\mathrm{SF}_{6}$ tracer gas was released at a known rate from permeation tubes placed per os in each steer's rumen prior to commencement of gas collection. Expired air was drawn continuously into an evacuated canister fitted to each animal's back via a capillary tube from tubes placed immediately above each animal's nose (attached to a headstall). Collection took place over 5 sequential, 2 day periods with background samples of $\mathrm{CH}_{4}$ and $\mathrm{SF}_{6}$ collected from 2 locations adjacent to the animals' pens.

Methane concentrations were measured using an Innova 1312 multi-gas analyser (Air Tech Instruments), and $\mathrm{SF}_{6}$ concentrations measured using gas chromatography (Goldsack et al., 1979). Samples having less than 1ppb SF ${ }_{6}$ or $30 \mathrm{ppm} \mathrm{CH}_{4}$ were eliminated from the study. $\mathrm{CH}_{4}$ emission was calculated by 
proportion (Johnson et al., 1994) and additionally expressed as a percentage of that predicted by the general equation of Blaxter and Clapperton (1965).

\section{RESULTS}

Overall mean $\mathrm{CH}_{4}$ production in Period 2 was $136.4 \mathrm{gd}^{-1}$ and did not differ between those steers that were identified as HIGH emitters or LOW emitters in the preliminary screening and in Period 1 (Table 1). HIGH and LOW emitters showed less divergence in $\mathrm{CH}_{4}$ production than in the earlier two studies and several animals changed from being more than, to less than predicted.

Table 1. Actual and predicted methane emissions on concentrate ${ }^{2}$ and forage based diets

\begin{tabular}{|c|c|c|c|c|c|c|c|}
\hline \multirow{2}{*}{ Animal, II } & & \multicolumn{2}{|c|}{$\begin{array}{l}\text { Initial screening } \\
\text { concentrate diet }\end{array}$} & \multicolumn{2}{|c|}{$\begin{array}{c}\text { Period } 1 \\
\text { concentrate diet }\end{array}$} & \multicolumn{2}{|c|}{$\begin{array}{l}\text { Period } 2 \\
\text { forage diet }\end{array}$} \\
\hline & & $\begin{array}{c}\mathrm{CH}_{4}, \mathrm{~g} \\
\text { produced }\end{array}$ & $\begin{array}{l}\mathrm{CH}_{4}(\%) \text { of } \\
\text { predicted }^{1}\end{array}$ & $\begin{array}{c}\mathrm{CH}_{4}, \mathrm{~g} \\
\text { produced }\end{array}$ & $\begin{array}{l}\mathrm{CH}_{4}, \% \text { of } \\
\text { predicted }^{1}\end{array}$ & $\begin{array}{c}\mathrm{CH}_{4}, \mathrm{~g} \\
\text { produced }\end{array}$ & $\begin{array}{l}\mathrm{CH}_{4}, \% \text { of } \\
\text { predicted }^{1}\end{array}$ \\
\hline \multirow{3}{*}{$\begin{array}{l}\text { HIGH } \\
\text { emitters }\end{array}$} & 145 & 376 & 169 & 173 & 74 & 127 & 95 \\
\hline & 102 & 328 & 148 & 243 & 101 & 212 & 119 \\
\hline & 134 & 308 & 133 & 204 & 77 & 115 & 69 \\
\hline \multirow{4}{*}{$\begin{array}{l}\text { LOW } \\
\text { emitters }\end{array}$} & 338 & 140 & 75 & 151 & 69 & 110 & 69 \\
\hline & 93 & 134 & 59 & 92 & 46 & 162 & 97 \\
\hline & 360 & 134 & 58 & 155 & 62 & 116 & 67 \\
\hline & 322 & 109 & 50 & 103 & 47 & 113 & 83 \\
\hline$P$ value & & & 0.0003 & & 0.038 & & 0.328 \\
\hline
\end{tabular}

${ }^{1}$ methane predicted to be produced from the equation of Blaxter and Clapperton (1965)

${ }^{2}$ results of earlier studies (Hegarty et al., 2004) are re-produced for comparison purposes

Methane production per unit of feed intake was also higher on the forage diet, increasing from a mean of $1.34 \mathrm{~g}$ to $2.26 \mathrm{~g} \mathrm{CH}_{4} / \mathrm{MJ} \mathrm{ME}$ intake.

\section{DISCUSSION}

Between animal variation in $\mathrm{CH}_{4}$ production has been quantified (Blaxter and Clapperton, 1965; Uylatt et al., 1999) and potential physiological mechanisms underlying genetic differences in ruminant digestion and $\mathrm{CH}_{4}$ production have recently been reviewed (Hegarty, 2004). The findings in this study that the characteristic of steers identified as $\mathrm{HIGH}$ or $\mathrm{LOW} \mathrm{CH}_{4}$ emitters was not maintained across diet types challenges the robustness of genetic selection of low $\mathrm{CH}_{4}$ emitting cattle. Similar results were observed in sheep (Pinares-Patino et al., 2003) where ranking of animals on the basis of emissions changed with alterations in the composition of diets. Genotype $\mathrm{x}$ nutrition interactions are recognized 
for many livestock production traits, and the results of this study indicate that selection for low methane production in cattle will need to be diet-specific. Failure of the general equation used to adequately reflect methane emissions also suggests that work needs to be done to develop more robust predictors of $\mathrm{CH}_{4}$ emission in ruminants.

\section{REFERENCES}

Blaxter K.L., Clapperton J.L., 1965. Prediction of the amount of methane produced by ruminants. Brit. J. Nutr. 19, 511-522

Crutzen P.J., Aselmann I., Seiler W., 1986. Methane production by domestic animals, wild ruminants and other herbivorous fauna and humans. Tellus - Chem. Phys. Meteorol. B 38, 271-284

Goldsack R.J., Hawke G.S., Tio P.H., 1979. Atmospheric dispersion experiments in the Sydney region. Clean Air 13, 57-61

Hegarty R.S., Woodgate R.T., Clark D.A., 2003. Performance of high-flow permeation tubes releasing $\mathrm{SF}_{6}$. Proceedings of Recent Advances in Animal Nutrition in Australia. University of New England, Armidale, NSW, 14, p. 19A

Hegarty R.S., Goopy J.P., Woodgate R.T., Machmuller A., 2004. Applying a modified SF procedure to screen cattle for low methane phenotype. Proceedings of International Conference Greenhouse Gas Emissions from Agriculture - Mitigation Options and Strategies. Leipzig (Germany), p. 276

Hegarty R.S., 2004. Genotype differences and their impact on digestive tract function of ruminants: a review. Aust. J. Exp. Agr. 61 (in press)

Johnson K.A., Huyler M.T., Westburg H.H., Lamb B.R., Zimmerman P., 1994. Measurement of methane emissions from ruminant livestock using a $\mathrm{SF}_{6}$ technique. Environ. Sci. Tech. 28, 359-362

Pinares-Patino C.S., Uylatt M.J., Lassey K.R., Barry N.T., Holmes C.W., 2003. Persistence of differences between sheep in methane emission under generous grazing. J. Agr. Sci. 140, 227-233

Ulyatt M.J., Baker S.K., McCrabb G.J., Lassey K.R., 1999. Accuracy of SF ${ }_{6}$ tracer technology and alternatives for field measurements. Aust. J. Agr. Res. 50, 1329-1334 